\title{
CORONARY FLOW RESERVE EARLY AND LATE AFTER MINIMALLY INVASIVE CORONARY ARTERY BYPASS GRAFTING IN PATIENTS WITH TOTALLY OCCLUDED LEFT ANTERIOR DESCENDING CORONARY ARTERY
}

\author{
Ruggero De Paulis, MD \\ Fabrizio Tomai, MD, FACC \\ Achille Gaspardone, MD, FACC \\ Luisa Colagrande, MD \\ Paolo Nardi, MD \\ Anna Ghini, MD \\ Francesco Versaci, MD, FACC \\ Alfonso Penta de Peppo, MD \\ Pier Agostino Gioffrè, MD \\ Luigi Chiariello, MD, FACC
}

\begin{abstract}
Background: The impairment of flow reserve of the left anterior descending coronary artery in the early postoperative period in patients receiving a left internal thoracic artery graft has been related to the effects of cardiopulmonary bypass. Indeed, the late improvement in flow has been attributed to a late increase in left internal thoracic artery diameter. Methods: We evaluated 12 patients who underwent minimally invasive direct coronary artery bypass surgery with the internal thoracic artery used to graft an occluded left anterior descending artery without extracorporeal circulation. Early and 6 months after the operation, patients underwent a second angiogram of the left internal thoracic artery graft and assessment of coronary flow reserve by use of an intracoronary 0.014-inch Doppler guide wire. Results: At the late study, coronary flow reserve had increased compared with the early postoperative data from $1.8 \pm 0.4$ (standard deviation) to $2.5 \pm 0.6(P=.002)$ because of a significant decrease in baseline averaged peak velocity $(32.4 \pm 6.2$ vs $21.3 \pm 6.4$ $\mathrm{cm} / \mathrm{s}, P=.002)$, whereas the hyperemic values were similar $(51 \pm 6 \mathrm{vs}$ $53.7 \pm 21.9 \mathrm{~cm} / \mathrm{s}, P=.6)$. The diameters of the thoracic artery $(2.1 \pm 0.3$ vs $2.2 \pm 0.3 \mathrm{~mm}, P=.7$ ) and the left anterior descending coronary artery $(1.8 \pm 0.1$ vs $1.8 \pm 0.2 \mathrm{~mm}, P=.5)$, as well as myocardial oxygen consumption (106 \pm 14 vs $101 \pm 16 \mathrm{~mm} \mathrm{Hg} \cdot$ beats $\left./ \mathrm{min} \cdot 10^{-2}, P=.5\right)$, were unchanged. Conclusions: Our findings suggest that the late improvement in coronary flow reserve is independent of the diameter of the graft and probably reflects an early distal coronary vessel dysfunction, which normalizes with time. (J Thorac Cardiovasc Surg 1999;118:604-9)
\end{abstract}

P ostoperative flow capacity of the left internal thoracic artery (LITA) has been reported to be inferior to that of saphenous vein grafts early after coronary artery bypass operations. This discrepancy has been studied with both radionuclide angiography and pulsed Doppler echocardiography. ${ }^{1-3}$ The latter method has demonstrated a higher peak flow velocity in the internal thoracic artery (ITA) than in saphenous veins. ${ }^{2}$ The recent development of an intracoronary Doppler guide wire that can be advanced intraluminally through the

From the Cardiac Surgery Division, University of Rome, Tor Vergata, Rome, Italy.

Received for publication Jan 22, 1999; revisions requested March 30, 1999; revisions received May 14, 1999; accepted for publication June 3, 1999.

Address for reprints: Ruggero De Paulis, MD, Cattedra di Cardiochirurgia, Università di Roma, Tor Vergata, European Hospital, via Portuense 700, 00149 Rome, Italy.

Copyright (C) 1999 by Mosby, Inc.

$0022-5223 / 99 \$ 8.00+0 \quad \mathbf{1 2 / 1 / 1 0 0 7 3 7}$ graft in the recipient coronary vessel has allowed a more accurate evaluation of flow velocities. ${ }^{4}$ Recently, Akasaka and colleagues, ${ }^{5}$ using a Doppler guide wire, found that in the early postoperative period the ITA had a higher resting velocity than the vein graft. This higher flow velocity was thought to be necessary to compensate for the small diameter of the ITA. However, with time they found a decrease in the resting flow velocity and an increase in the diameter of the vessel, with a consequent improvement in flow capacity. Part of these differences might also be ascribed to the effects of cardiopulmonary bypass (CPB) on vascular reactivity in the early postoperative period. Recently, a new surgical technique has been introduced into practice. It consists of anastomosing the LITA to the left anterior descending coronary artery (LAD) on the beating heart through a small anterior thoracotomy (minimally invasive direct coronary artery bypass graft, MIDCABG operation) without the need for CPB. ${ }^{6}$

The purpose of this study was to assess the flow 
capacity of the LITA early and late after the MIDCABG operation using a Doppler guide wire to eliminate the effects of CPB in modifying the flow reserve of the grafted coronary vessels.

\section{Patients and methods}

From February 1996 to December 1997, 32 consecutive patients received an LITA on the LAD on the beating heart via a left anterior small thoracotomy. The majority of patients selected for this type of procedure had a single lesion of the LAD with symptoms or signs of ischemia; few patients were selected because of a presumed high morbidity with CPB. From this group we selected 12 patients (11 men, mean age $59 \pm 7$ years) with good ventricular function and a totally occluded LAD for the study. Three patients were in preoperative Canadian Cardiovascular Society class II, 4 in class III, and 5 in class IV. The mean ejection fraction was $52 \% \pm 11 \%$. Six patients had a previous anterior myocardial infarction. Four patients had a second untreated stenosis of a secondary coronary vessel. All patients gave written informed consent for participation in the study, which was approved by the Institutional Ethics Committee of the University of Rome.

Surgical technique. The surgical technique is the same as described by Calafiore, Di Giammarco, and Teodori. ${ }^{6}$ In brief, the chest is opened in the 4th intercostal space and the LITA is harvested for a length of at least $10 \mathrm{~cm}$. The pericardium is opened and the spatial relationship of the LITA with the LAD is assessed. After systemic heparinization (1 $\mathrm{mg} / \mathrm{kg}$ ), the LITA is clamped and prepared as usual. The site of anastomosis of the LAD is dissected. The LAD is then occluded proximally and distally by means of 2 size 4-0 Prolene sutures (Ethicon, Inc, Somerville, NJ) passed twice around the vessel and rubber shod at the point where they compress the coronary artery. The LAD is then opened with a sharp knife and the anastomosis is performed by means of 2 continuous sutures of 8-0 Prolene polypropylene starting at the toe and at the heel of the anastomotic site. In the more recent cases, a commercially available instrument (United States Surgical Corporation, Norwalk, Conn) has been used in stabilizing the artery during the anastomosis. After completion of the anastomosis, the clamps are removed and the chest is closed.

Postoperative evaluation. Between 24 and 48 hours after the operation all patients underwent cardiac catheterization and angiography of the LITA. Drugs that could affect hemodynamics were not used before the procedure. Through a femoral approach, selective angiography of the LITA was carried out and the patency of the arterial graft onto the LAD was assessed. Arterial blood pressure throughout the guiding catheter positioned into the LITA and 3 electrocardiographic leads were recorded during the procedure, and the rate-pressure product (systolic blood pressure $\times$ heart rate) was used as an index of myocardial oxygen consumption. Quantitative angiography was performed by computer-assisted digital analysis with the Philips DCI system (Philips Medical Systems, Irvine, Calif). The guiding catheter was used as a reference standard. Off-line analysis of the cross-sectional area and diameter of the distal tract of the LAD and of the LITA graft was performed by use of the quantitative cardiovascular software program ACA (Philips DCI). After angiography, a 0.014-inch Doppler-tipped guide wire (FloWire and FlowMap, Cardiometrics, Inc, Lake Success, NY) was advanced through the 7F guiding catheter into the LITA graft and then positioned in the LAD until an optimal and stable Doppler signal, not in the proximity of a side branch, was obtained. Blood flow velocity was calculated from the Doppler frequency shift of a reflected $15-\mathrm{MHz}$ signal by fast Fourier transformation and displayed in a spectral format. Flow velocity signals were continuously displayed throughout the study. Average peak velocity (APV, centimeters per second) and diastolic/systolic flow velocity ratio were derived automatically by the integrated signal-analyzing computer. Satisfactory velocity data were obtained for all 12 patients. After on-line assessment of the baseline APV, hyperemia was induced by administration of an intra-LITA bolus of adenosine $(20 \mu \mathrm{g})$. Coronary flow reserve ratio was calculated as the maximal hyperemic APV/basal APV. Dopplerderived flow $\left(Q_{D}\right.$, milliliters per minute) in the LAD was also calculated by means of the following validated formula ${ }^{4}$ :

$$
\mathrm{Q}_{\mathrm{D}}=\mathrm{CSA} \cdot(0.5 \cdot \mathrm{APV})
$$

where CSA is the cross-sectional area as measured at the tip of the Doppler wire and 0.5 . APV is the mean velocity. Patients underwent the same procedure and followed the same protocol after a mean period of 7.2 \pm 3.2 months from the operation (range 3-13 months).

Statistical analysis. Comparisons of hemodynamic, anatomic, and Doppler-derived variables between the early and late evaluations after the operation were made by a paired $t$ test. Early and late postoperative hyperemic and basal Doppler-derived data were compared by a 2-way analysis of variance for repeated measures, with the Scheffé $F$ test for post hoc multiple comparisons. All data are expressed as mean value \pm standard deviation.

\section{Results}

No perioperative mortality or morbidity occurred. The mean duration of the operation was $120 \pm 20$ minutes and the patients were kept in the intensive care unit for an average of $8 \pm 4$ hours. The postoperative levels of troponin I were within the limits of normal $(0.048 \pm$ $0.06 \mathrm{ng} / \mathrm{mL}$; normal range $0.0-0.1 \mathrm{ng} / \mathrm{mL}$ ). All patients were discharged on the 4th postoperative day.

During the early postoperative study, all anastomoses were patent with complete visualization of the LAD from the apex to the point of proximal occlusion. Few irregularities in the normal contours of the LITA and at the level of the anastomosis were noted (Fig 1). The baseline APV was $32.4 \pm 6.2 \mathrm{~cm} / \mathrm{s}$ and the hyperemic APV was $51.6 \pm 6 \mathrm{~cm} / \mathrm{s}$, with a calculated coronary flow reserve of $1.8 \pm 0.4$. Diastolic/systolic velocity 


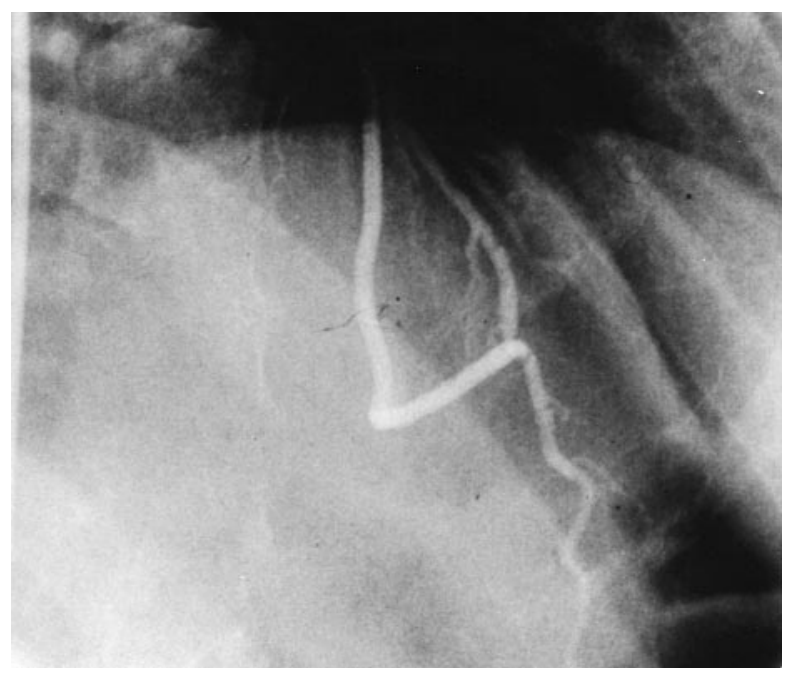

Fig 1. Early postoperative angiogram of a LITA bypass graft to the LAD. Small irregularities are evident at the level of anastomotic site and at the site of clamping of the coronary artery during the operative time $(1 \mathrm{~cm}$ above and below the anastomosis).

ratio was $1.4 \pm 0.6$ (Fig 2). The mean diameter of the LITA immediately proximal to the anastomosis with the LAD was $2.1 \pm 0.3 \mathrm{~mm}$, and the mean diameter of the LAD immediately distal to the anastomosis was 1.8 $\pm 0.1 \mathrm{~mm}$. Baseline Doppler-derived flow was $41 \pm 8$ $\mathrm{mL} / \mathrm{min}$ and hyperemic flow was $65 \pm 16 \mathrm{~mL} / \mathrm{min}$ with a hyperemic/basal Doppler-derived flow of $1.6 \pm 0.2$ (Table I). Heart rate, systolic blood pressure, and ratepressure product were similar at baseline and during the hyperemic response (Table I).

At the time of follow-up and of the second hemodynamic study all patients were asymptomatic and were back to their normal working activity. Angiography confirmed the patency of the anastomoses and the disappearance of the small irregularities that were present at the early angiographic examination (Fig 3). The baseline APV was $21.3 \pm 6.4 \mathrm{~cm} / \mathrm{s}$ and the maximal APV was $53.7 \pm 21.9 \mathrm{~cm} / \mathrm{s}$ with a calculated flow reserve of $2.5 \pm 0.6$. Diastolic/systolic velocity ratio was $1.4 \pm 0.3$. The mean diameter of the LITA was 2.2 $\pm 0.3 \mathrm{~mm}$ and the mean diameter of the LAD was 1.8 $\pm 0.2 \mathrm{~mm}$. Baseline Doppler-derived flow was $24 \pm 8$ $\mathrm{mL} / \mathrm{min}$ and hyperemic flow was $61 \pm 23 \mathrm{~mL} / \mathrm{min}$ with a hyperemic/basal Doppler-derived flow of $2.5 \pm 0.7$. Heart rate, systolic blood pressure, and rate-pressure product were similar at baseline and during the hyperemic response (Table I).

Between the early and late studies the basal APV decreased significantly whereas the hyperemic APV was not modified, thus yielding a significant difference in coronary flow reserve: $1.8 \pm 0.4$ vs $2.5 \pm 0.6(P=$ .002). The increase in LAD flow reserve between the 2 studies was $47 \% \pm 34 \%$. Similar results were also obtained with the use of Doppler-derived flow indices. Of note, there were no significant differences between heart rate, systolic blood pressure, and rate-pressure product recorded during early angiographic studies and those recorded at follow-up (Table I).

\section{Discussion}

Various methods have been used to measure coronary flow velocity, such as extravascular Doppler probes applied directly to the surface of coronary arteries in open chest procedures and transesophageal or transthoracic echocardiography with the possibility to assess only the very proximal tract of the coronary arteries. ${ }^{7,8}$ Indirect measurements of the postoperative flow reserve have been obtained by means of thallium scintigraphy or radionuclide techniques. ${ }^{9}, 10$ The use of an intravascular device was introduced in the 1970s, but the most important problem with this catheterbased Doppler system was the large diameter (about 1 $\mathrm{mm}$ ), which affected blood flow and disturbed the velocity profile. ${ }^{11}$ This problem was recently overcome with the introduction of 0.014 - and 0.018 -inch intravascular Doppler guide wires, which have been shown to provide accurate measurements of coronary flow reserve. ${ }^{4}$ Using this new method in patients undergoing coronary artery bypass surgery with $\mathrm{CPB}$, Akasaka and colleagues ${ }^{5}$ found a higher resting flow velocity in the LITA on the LAD than in saphenous vein grafts in the early postoperative period. This restricted flow capacity was found to improve later because of an increase of the LAD diameter.

In our study we wanted to clarify the factors causing these early alterations of flow, considering only patients who underwent MIDCABG surgery. In contrast to previous investigators, we did not find a significant increase in the LITA diameter at the late study; nonetheless, we did observe a significant reduction in basal APV with an increase in the coronary flow reserve from 1.8 to 2.5 . Thus our findings suggest that the improvement in coronary flow reserve cannot be ascribed only to the increasing diameter of the graft, as in the study of Akasaka and colleagues, but that other factors clearly influence the early restricted postoperative flow capacity.

Our findings are in agreement with those of Wilson and associates, ${ }^{12}$ who found that in about $50 \%$ of patients undergoing successful percutaneous transluminal coronary angioplasty, coronary flow reserve early 


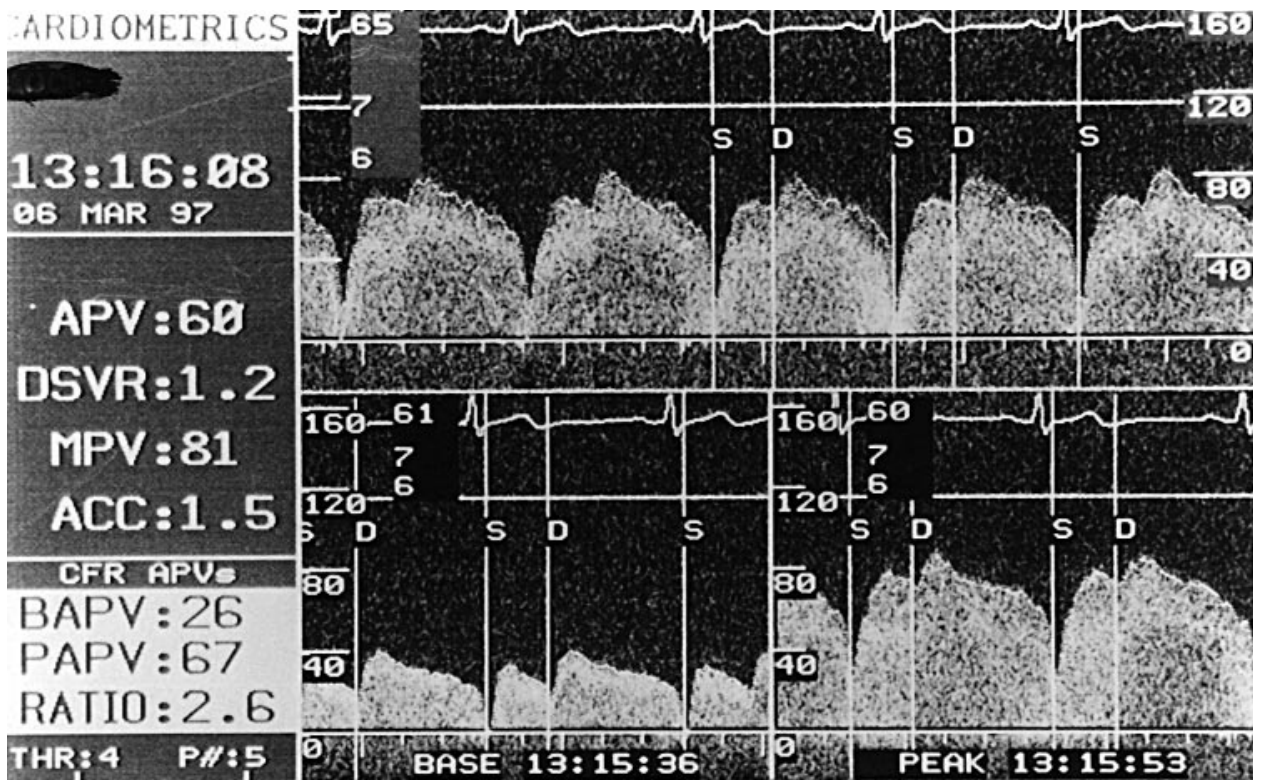

Fig 2. Representative example of flow velocity pattern of the LITA anastomosed to the LAD before and after maximal vasodilation with a bolus of adenosine in 1 patient at the late postoperative study. Note that the diastolic flow velocities are always higher than the systolic flow velocities and the coronary flow reserve (peak APV/baseline APV) value is similar to that of a normal coronary artery. Upper panel, Real time recording during adenosine administration. Lower left panel, Baseline flow velocity. Lower right panel, Hyperemic flow velocity. $S$, Systole; $D$, diastole.

Table I. Early and late postoperative hemodynamic, anatomic and Doppler-derived variables

\begin{tabular}{lccc}
\hline & Early & Late & P value \\
\hline Basal APV $(\mathrm{cm} / \mathrm{s})$ & $32.4 \pm 6.2$ & $21.3 \pm 6.4$ & .002 \\
Hyperemic APV $(\mathrm{cm} / \mathrm{s})$ & $51.6 \pm 6$ & $53.7 \pm 21.9$ & .6 \\
CFR & $1.8 \pm 0.4$ & $2.5 \pm 0.6$ & .002 \\
DSVR & $1.4 \pm 0.6$ & $1.4 \pm 0.3$ & .9 \\
LITA diameter $(\mathrm{mm})$ & $2.1 \pm 0.3$ & $2.2 \pm 0.3$ & .7 \\
LAD diameter $(\mathrm{mm})$ & $1.8 \pm 0.1$ & $1.8 \pm 0.2$ & .5 \\
Basal $\mathrm{Q}_{\mathrm{D}}(\mathrm{mL} / \mathrm{min})$ & $41 \pm 8$ & $24 \pm 8$ & .002 \\
Hyperemic $\mathrm{Q}_{\mathrm{D}}(\mathrm{mL} / \mathrm{min})$ & $65 \pm 16$ & $61 \pm 23$ & .5 \\
Hyperemic $\mathrm{Q}_{\mathrm{D}} / \mathrm{basal} \mathrm{Q}_{\mathrm{D}}$ & $1.6 \pm 0.2$ & $2.5 \pm 0.7$ & .004 \\
SBP $(\mathrm{mm} \mathrm{Hg})$ & $120 \pm 8$ & $125 \pm 10$ & .2 \\
$\mathrm{HR}($ beats $/ \mathrm{min})$ & $88 \pm 5$ & $81 \pm 7$ & .06 \\
RPP $(\mathrm{mm} \mathrm{Hg} \cdot$ & $106 \pm 14$ & $101 \pm 16$ & .5 \\
beats/min $\left.\cdot 10^{-2}\right)$ & & & \\
\hline
\end{tabular}

$A P V$, Time-averaged peak velocity; $C F R$, coronary flow reserve; $D S V R$, diastolic/systolic velocity ratio; LITA, left internal thoracic artery; $L A D$, left anterior descending coronary artery; $Q_{D}$, Doppler-derived flow; $S B P$, systolic blood pressure; $H R$, heart rate; $R P P$, rate-pressure product.

after the procedure was reduced, despite the absence of residual stenosis. Furthermore, our group previously found a regional reduction in coronary flow reserve in $44 \%$ of patients undergoing successful stent implanta-

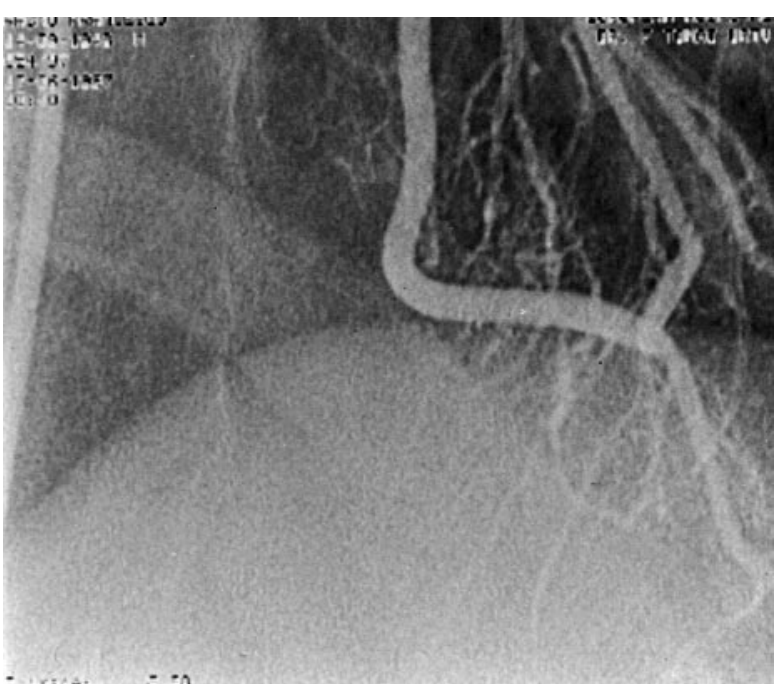

Fig 3. Late postoperative angiogram of the same bypass graft as in Fig 1. Even at a higher magnification, there is no evidence of the filling defects that were present at the early study.

tion, which has been shown to provide optimal immediate anatomic result. ${ }^{13}$ Therefore, as repeated angiography in our patients showed patent anastomoses, early reduction in coronary flow reserve was probably 
caused by distal coronary vessel dysfunction in the myocardial regions supplied by the grafted vessel. This, in turn, might have been caused by the vessel wall damage associated with its compression during the anastomotic time (ie, surgical technique), resulting in platelet adhesion and aggregation with local release of vasoactive substances or distal microembolization in the same manner as described after angioplasty and stent implantation. ${ }^{14,15}$ Distal vessel constriction might also have been caused by the sudden increase in poststenotic (more appropriately postocclusion in our cases) pressure after revascularization, as suggested by Fishell, Bausback, and McDonald ${ }^{16}$ during angioplasty. The improvement in coronary flow reserve 6 months after the intervention, with myocardial oxygen consumption and LITA and LAD diameters being unchanged (see Table I), supports the concept that the impaired flow reserve observed in this study early after MIDCABG was due to functional rather than organic causes. Such findings may also account for the failure to accurately predict the long-term success of coronary revascularization procedures on the basis of an early assessment of coronary flow reserve. ${ }^{17}$

Previous studies demonstrated that the LITA graft has flow adaptability responding to flow demand of the recipient coronary artery, so that the graft flow decreases when a lower-degree stenosis of the LAD is present. ${ }^{18,19}$ These findings demonstrate that native coronary artery flow in patients with moderate stenosis competes with LITA flow, likely because mean diastolic pressure in the LITA is lower than in the LAD, or because of large collaterals proximal to the anastomosis that may cause "steal phenomena," or for competition with the flow of saphenous grafts implanted near the LITA anastomosis. ${ }^{20,21}$ By measuring the flow in patients with a totally occluded LAD in the tract distal to the anastomosis, we eliminated many of these problems, because the blood supply to the LAD was exclusively coming from the LITA. The coronary flow reserve of the recipient coronary vessel was therefore estimated without inferences on the possibility that the LITA could not act simply as a conduit, but could somehow modulate the coronary flow.

No significative modifications in blood flow velocity waveform or in the diastolic/systolic velocity ratio were observed between early postoperative and follow-up data in any of our patients, confirming the presence of a diastolic dominant circulation as an indirect sign of the good hemodynamic performance of the grafts. We cannot exclude the fact that, in patients with a totally occluded LAD, we did not find the improvement in LITA diameter that would have been obtained in patients with LAD stenosis that slowly progressed to total occlusion with a consequent increase in LITA diameter.

Finally, the increase in shear stress induced by increase of flow during exercise enhances the production of nitric oxide. ${ }^{22}$ Furthermore, there is a relative impairment of this endothelial function in patients with coronary artery disease, with reduction of epicardial coronary artery dilation in response to myocardial work. ${ }^{23,24}$ The presence of a flow-limiting stenosis impairs the release of nitric oxide, altering the flowmediated coronary arterial dilation. ${ }^{25}$ Thus we can speculate that in the occluded LAD, as was the case in our study, the impaired release of nitric oxide could improve in the late postoperative period by restoring a normal and antegrade blood supply through the LITA with an increase in shear stress. The consequent increase of nitric oxide release should lead to a reduction of coronary resistances and an increase in coronary flow reserve.

\section{Conclusions}

Our study rules out the possibility that the late improvement in coronary flow reserve in patients undergoing MIDCABG is due to an increase of LITA diameter and demonstrates that other factors play an important role in influencing vascular reactivity with a late improvement of coronary flow reserve after antegrade flow has been restored. Both the presence of small thrombotic material around the anastomosis that has disappeared at the follow-up study and transient small coronary vessel dysfunction seem to be important factors in determining the change in coronary flow reserve with time.

The restoration of antegrade flow in a totally occluded artery suggests a potential normalization of the nitric oxide-dependent vasodilation.

A control group of patients operated on with CPB would have given more insights into the pathophysiology of coronary flow reserve after coronary bypass. However, the paucity of patients undergoing CPB for a single occlusive lesion of the LAD due to the present tendency of performing a less invasive procedure (angioplasty or MIDCABG) prevented us from completing this part of the study.

\section{REFERENCES}

1. Fujiwara T, Kajiya F, Kanazawa S, et al. Comparison of bloodflow velocity waveforms in different coronary artery bypass grafts: sequential saphenous vein grafts and internal mammary artery grafts. Circulation 1988;78(5 Pt 1):1210-7.

2. Fusejima K, Takahara Y, Sudo Y, Murayama H, Masuda Y, Inagaki Y. Comparison of coronary hemodynamics in patients with internal mammary artery and saphenous vein coronary 
artery bypass grafts: a noninvasive approach using combined two-dimensional and Doppler echocardiography. J Am Coll Cardiol 1990;15:131-9.

3. Kawasuji M, Tsujiguchi H, Tedoriya T, Taki J, Iwa T. Evaluation of postoperative flow capacity of internal mammary artery. J Thorac Cardiovasc Surg 1990;99:696-702.

4. Doucette JW, Corl PD, Payne HM, et al. Validation of a Doppler guidewire for intravascular measurement of coronary artery flow velocity. Circulation 1992;85:1899-911.

5. Akasaka T, Yoshikawa J, Yoshida K, et al. Flow capacity of internal mammary artery grafts: early restriction and later improvement assessed by Doppler guide wire: comparison with saphenous vein grafts. J Am Coll Cardiol 1995;25:640-7.

6. Calafiore AM, Di Giammarco G, Teodori G. Left anterior descending coronary artery grafting via left anterior small thoracotomy without cardiopulmonary bypass. Ann Thorac Surg 1996;61:1658-65.

7. Iliceto S, Marangelli V, Memmola C, Rizzon P. Transesophageal Doppler echocardiography evaluation of coronary blood flow velocity in baseline conditions and during dipyridamole-induced coronary vasodilation. Circulation 1991;83:61-9.

8. Takemura H, Kawasuji M, Sakakibara N, Tedoriya T, Ushijima T, Watanabe Y. Internal thoracic artery graft function during exercise assessed by transthoracic Doppler echography. Ann Thorac Surg 1996;61:914-9.

9. Johnson AM, Kron IL, Watson DD, Gibson RS, Nolan SP. Evaluation of postoperative flow reserve in internal mammary artery bypass grafts. J Thorac Cardiovasc Surg 1986;92:822-6.

10. Schmidt DH, Blau F, Hellman C, Grzlak L, Johnson WD. Isoproterenol-induced flow responses in mammary and vein bypass grafts. J Thorac Cardiovasc Surg 1980;80:319-26.

11. Cole JS, Hartley CJ. The pulsed Doppler coronary artery catheter: preliminary report of a new technique for measuring rapid changes in coronary artery blood flow velocity in man. Circulation 1977;56:18-25.

12. Wilson RF, Johnson MR, Marcus ML, et al. The effect of coronary angioplasty on coronary flow reserve. Circulation 1988;77:873-85.

13. Versaci F, Tomai F, Nudi F, et al. Differences of regional coronary flow reserve assessed by adenosine thallium-201 scintigraphy early and six months after successful percutaneous transluminal coronary angioplasty or stent implantation. Am J Cardiol 1996; 78:1097-102.
14. Segal J, Kern MJ, Scott NA, et al. Alterations of phasic coronary artery flow velocity in humans during percutaneous coronary angioplasty. J Am Coll Cardiol 1992;20:276-86.

15. Bates ER, Aueron FM, Legrand V, et al. Comparative long-term effects of coronary artery bypass graft surgery and percutaneous transluminal coronary angioplasty on regional coronary flow reserve. Circulation 1985;72:833-9.

16. Fishell TA, Bausback KN, McDonald TV. Evidence for altered epicardial coronary artery autoregulation as a cause of distal coronary vasoconstriction after successful percutaneous transluminal coronary angioplasty. J Clin Invest 1990;86:575-84.

17. Manyari DE, Knudtson M, Kloiber R, Roth D. Sequential thallium-201 myocardial perfusion studies after successful percutaneous coronary artery angioplasty: delayed resolution of exercise-induced scintigraphic abnormalities. Circulation 1988;77: 86-95.

18. Nasu M, Akasaka T, Okazaki T, et al. Postoperative flow characteristics of left internal thoracic artery grafts. Ann Thorac Surg 1995;59:154-62.

19. Seki T, Kitamura S, Kawachi K, et al. A quantitative study of postoperative luminal narrowing of the internal thoracic artery graft in coronary artery bypass surgery. J Thorac Cardiovasc Surg 1992;104:1532-8.

20. Tedoriya T, Kawasuji M, Ueyama K, Sakakibara N, Takemura H, Watanabe Y. Physiologic characteristics of coronary artery bypass graft. Ann Thorac Surg 1993;56:951-6.

21. Schmid C, Heublein B, Reichelt S, Borst HG. Steal phenomenon caused by a parallel branch of the internal mammary artery. Ann Thorac Surg 1990;50:463-4.

22. Furchgott RF, Zawadki JV. The obligatory role of endothelial cells in the relaxation of arterial smooth muscle by acetylcholine. Nature 1980;288:373-6.

23. Quyyumi AA, Dakak N, Andrews NP, Gilligan DM, Panza JA, Cannon RO. Contribution of nitric oxide to metabolic coronary vasodilation in the human heart. Circulation 1995;92:320-6.

24. Tousoulis D, Tentolouris C, Crake T, Toutouzas P, Davies G. Basal and flow-mediated nitric oxide production by atheromatous coronary arteries. J Am Coll Cardiol 1997;29:1256-62.

25. Schwartz JS, Baran KW, Bache RJ. Effect of stenosis on exercise-induced dilation of large coronary arteries. Am Heart J 1990; 110:520-4. 